\title{
PARTICIPAÇÃO POPULAR, PODER E FORMAÇÃO DA CIDADANIA: UM ESTUDO POLÍTICO-PEDAGÓGICO DO ORÇAMENTO PARTICIPATIVO
}

\author{
Danilo Romeu Streck (Unisinos)*
}

\begin{abstract}
RESUMO
O artigo analisa a relação entre participação popular, poder e cidadania a partir de estudo sobre o orçamento participativo no Estado do Rio Grande do Sul (Brasil). O argumento central é que a participação na definição de projetos e prioridades é uma prática social privilegiada de formação da cidadania. O estudo está baseado numa metodologia participativa, tendo como princípio o diálogo com os diversos setores envolvidos. Como conclusão, aponta-se o potencial político-pedagógico do orçamento participativo através da leitura coletiva da realidade, e a importância de espaços públicos de discussão para a reconstrução de relações de poder.

Palavras-chaves: Orçamento participativo. Poder. Participação. Pedagogia do poder.
\end{abstract}

\section{ABSTRACT \\ POPULAR PARTICIPATION, POWER AND CITIZENSHIP EDUCATION: A PEDAGOGICAL-POLITICAL STUDY OF THE PARTICIPATORY BUDGET}

The article analyses the relationship between popular participation, power and citizenship, based on studies on participatory budgeting in the state of Rio Grande do Sul (Brasil). The central argument is that participation in the definition of projects and priorities is a privileged social practice for citizenship education. The study is based on a participatory methodology which has as leading principle the dialogue with the different stakeholders. As conclusion the article highlights the political-pedagogical potential of the collective reading of reality, as well as the importance of public discussion spaces for the reconstruction of power relations.

Keywords: Participatory budget. Power. Participation. Pedagogy of power.

\section{RESUMEN}

\section{PARTICIPACIÓN POPULAR, PODER Y FORMACIÓN DE LA CIUDADANÍA: UN ESTUDIO POLÍTICO-PEDAGÓGICO DEL PRESUPUESTO PARTICIPATIVO}

El artículo analiza la relación entre participación popular, poder y ciudadanía, desde el presupuesto participativo en el estado de Rio Grande do Sul (Brasil). El argumento central es que la participación en la definición de proyectos y prioridades es una práctica social privilegiada de educación ciudadana. El estudio tiene por base una metodología

\footnotetext{
* Doutor em Educação pela Rutgers University (EUA). Professor/pesquisador do Programa de Pós-Graduação em Educação da Universidade do Vale do Rio dos Sinos (PPGE/Unisinos). Membro do grupo de pesquisa Mediações Pedagógicas e Cidadania, vinculado à Universidade do Vale do Rio dos Sinos (Unisinos). E-mail: streckdr@gmail.com
} 
participativa cuyo principio orientador es el diálogo con los diferentes participantes. La conclusión apunta para el potencial político-pedagógico de la lectura colectiva de la realidad, bien como la importancia de espacios públicos para la reconstrucción de relaciones de poder.

Palabras Clave: Presupuesto participativo. Poder. Participación. Pedagogía del poder.

\section{Introdução}

A formação da cidadania, embora nem sempre explicitada na pauta pedagógica dadas prioridades consideradas mais imediatas, é requisito central para qualquer sociedade com ambições democráticas. Ninguém põe em dúvida hoje o fato de que há conhecimentos e práticas que legitimam diferentes formas de poder, desde governos democráticos a governos autoritários, desde uma ciência comprometida com a preservação e promoção da vida a uma ciência a serviço de lucros fáceis. Há conhecimentos ou saberes de resistência, de insurgência e de opressão. Também a participação pode ter significados muito diferentes, desde a manipulação até a assunção conjunta, dialogada e crítica de projetos e ideais (FRICKE, 2013; STRECK, 2013).

O texto parte do pressuposto defendido por Paulo Freire de que a história é possibilidade e não determinação (FREIRE, 1991); que, conforme Eduardo Galeano (1994), as utopias são feitas para se andar porque elas apontam um horizonte que se desloca na medida em que avançamos em sua direção; que, segundo Peter Reason (2002), fazer pesquisa pode representar o compromisso com a construção de uma visão de mundo participativa. Isso não significa fechar os olhos para o fato de que ninguém é imune aos assédios da mosca azul do poder (FREI BETTO, 2006). Em nível mundial, a concentração do poder econômico (PIKETTI, 2014) reserva um espaço limitado e "seguro" para a participação dos cidadãos. E o acesso ao conhecimento e aos meios de produção de conhecimento continua gerando desigualdades, apesar das (ou também por causa?) inúmeras novas formas de comunicação (HIDMAN, 2009).

O pressuposto é de que essas três dimensões - participação, poder e formação da cidadania estão intrinsecamente interligadas. No abstrato, o tema pode levar a infindáveis discussões. Pretendo nesse exercício partir não de determinadas teorias, mas estar atento às emergências em uma prática social que talvez tenha perdido um pouco de seu charme e apelo ideológico, mas que ainda se situa na vanguarda de experiências democráticas inovadoras. Refiro-me ao orçamento participativo, que no Brasil teve sua experiência pioneira em Porto Alegre, a partir do ano de 1989. Foi um período de entusiasmo com a promulgação da nova constituição brasileira, em 1988, que abria espaço para a participação do povo por demanda da sociedade civil, após duas décadas de ditadura militar. No plano internacional, 1989 é também o ano da queda do muro de Berlim e a época da afirmação do chamado "consenso de Washington" como a proposta político-econômica neoliberal que marcaria a nova globalização. É a sociedade se movimentando entre embates que ainda hoje fazem parte do cenário político e social.

O subtítulo indica o lugar de onde é feita a reflexão, bem como o direcionamento da discussão. Ao referir que realizo a reflexão na perspectiva da área da educação, desejo manifestar minha consciência de que um olhar filosófico, da ciência política ou da sociologia produziria outro texto. Ao mesmo tempo, reafirmo a importância do que Orlando Fals Borda (2010a) chama de convergências disciplinares. Essas convergências, por sua vez, podem representar também transgressões disciplinares em vista de uma nova rigorosidade, conforme argumentava Paulo Freire (1996). Não uma rigorosidade de adesão a cânones teóricos fechados ou à repetição de práticas, mas a assunção do risco de pensar a prática.

Ao direcionar o tema para o que denomino pedagogia do poder, desejo realçar que participar e conhecer, seja através do ensino ou da pesquisa, são sempre ações políticas, isto é, estão tramadas dentro das relações de força onde se decide a vida do indivíduo e da sociedade. $\mathrm{O}$ fato de privilegiar essa perspectiva tem a ver também com a constatação de que apesar de a grande maioria dos estados-nação 
se definirem como democráticos, as manifestações sociais e protestos que periodicamente explodem em todos os continentes são uma expressão de que há uma distância entre o formalmente proposto e a prática cidadã possível.

$\mathrm{Na}$ primeira parte do texto são apresentados elementos para que o leitor compreenda o contexto empírico e a metodologia do estudo. O orçamento participativo é hoje uma prática político-administrativa amplamente difundida, especialmente em administrações municipais, e deixou de ser uma marca exclusiva do Partido dos Trabalhadores, como era em sua origem. O objeto deste estudo é a experiência com orçamento participativo no estado do Rio Grande do Sul, ou seja, numa escala geográfica e populacional ampliada.

No tópico da metodologia é apresentada a perspectiva epistemológica que orienta o estudo, algumas das estratégias utilizadas na coleta e análise dos dados e a reflexão sobre a pesquisa como parte de um complexo de relações e de poder dentro do qual se geram conhecimentos. A pesquisa, como entendida neste texto, faz parte da pedagogia do poder e por isso lhe é dedicado um espaço relativamente amplo.

$\mathrm{O}$ texto converge para o que poderiam ser contribuições para uma pedagogia do poder. Se desejarmos que o poder deixe de ser um objetivo para o qual se educa no sentido de proporcionar vantagens em termos de capacidade de consumo ou de status social dentro de um mercado altamente competitivo, mas uma força mobilizadora para a justiça social, então se faz necessário transformar o poder num tema pedagógico. Ao referir-me a uma pedagogia do poder não penso necessariamente ou apenas em salas de aula, mas em todos os processos sociais com uma intencionalidade educativa, entre eles a pesquisa social. No espaço deste texto pode-se apenas anunciar uma temática a ser explorada em outros estudos e com outros interlocutores.

\section{Um experimento de democracia participativa}

A legislação brasileira estabelece os parâmetros gerais para a elaboração do orçamento público em todos os níveis da Federação. O processo é constituído por três etapas, todas elas baseadas em projetos de lei de competência exclusiva do Poder Executivo: o plano plurianual, elaborado pelo Poder Executivo no início do mandato e submetido à aprovação da Assembleia Legislativa; a lei de diretrizes orçamentárias, igualmente encaminhada pelo Executivo ao Legislativo, que fixa as normas e grandes linhas do planejamento anual; o orçamento anual, que passa pelo mesmo processo de aprovação, e que deve ser compatibilizado de acordo com o plano plurianual e a lei de diretrizes orçamentárias.

Esse dado é relevante para entender por que a implementação de modalidades diferentes de orçamento público depende, dentro de um quadro legal relativamente aberto, do projeto de governo e da vontade política do Poder Executivo eleito. No estado do Rio Grande do Sul, que é o contexto de referência neste artigo, passou-se por várias alternativas de participação popular, revelando rupturas e continuidades. ${ }^{1} \mathrm{O}$ começo pode ser situado em 1994, quando são criados no estado os Conselhos Regionais de Desenvolvimento (COREDES), hoje em número de 28 , que têm o papel de favorecer um planejamento integrado de municípios de acordo com características culturais e potencialidades econômicas regionais (SIEDENBERG, 2008). Essa instância de organização social e política desde então é uma referência importante para o planejamento estratégico no estado e representa uma base institucional para a participação dos cidadãos, podendo tanto apoiar quanto obstaculizar políticas do governo estadual eleito.

Em 1998 cria-se uma consulta popular sobre prioridades na alocação dos recursos. É um mecanismo simples, possivelmente mais inspirado no receio de uma iminente vitória da coligação partidária liderada pelo Partido dos Trabalhadores, que tem como uma de suas bandeiras o orçamento participativo, do que por uma convicção política. De fato, com a vitória da Frente Popular liderada pelo Partido dos Trabalhadores implantou-se em 1999 o orçamento participativo estadual baseado nos

1 Há importantes experiências participativas na gestão pública que antecederam a criação do orçamento participativo em Porto Alegre. Dentre elas encontram-se o programa "Desenvolvimento e organização de comunidades" (MARQUES; BRUM, 2002), iniciado em 1961, e a experiência de administração pública municipal de Pelotas, conhecida como "Todo o poder emana do povo" (SOUZA, 2002), no início da década de 1980. 
princípios da experiência de Porto Alegre (HORN, 1994). Foi uma experiência arrojada e pioneira por implantar em nível estadual, para uma população de mais de 10 milhões de habitantes, um sistema de participação direta dos cidadãos na destinação de parcela dos recursos públicos e, o que talvez seja mais importante, na discussão aberta dos gastos e das receitas do estado (MARQUES, 1999).

Houve na época um grande debate sobre a eventual ilegalidade do processo a partir da Assembleia Legislativa, que sentiu seu espaço invadido pelo povo. E literalmente foi assim: houve assembleias públicas nas quais deputados estaduais foram impedidos de falar e inclusive instados a deixar o local. Era o sinal de que o povo reivindicava este espaço como sendo seu, evidenciando também a insatisfação com a forma de delegação de poder através da eleição periódica de representantes.

Nas duas administrações que se seguiram, a participação em questões orçamentárias foi basicamente restrita à consulta, através do voto, sobre projetos previamente definidos (SOBOTTKA; SAAVEDRA; ROSA, 2005). Deixaram de existir reuniões com centenas de pessoas discutindo e apresentando as suas propostas, às vezes de forma bastante dramática. Por exemplo, em uma das reuniões uma professora levou uma caixa de papelão com cópias de cartas dirigidas aos órgãos públicos e as espalhou diante dos presentes em forma de protesto. Importante destacar, no entanto, que mesmo que a participação fosse efetivamente restringida, o discurso era de que se tratava de seu aperfeiçoamento. Seria isso evidência de que, como argumenta Guimarães (2004), uma nova cultura política estava se formando e exigindo ao menos formalmente espaços de participação? É demasiado cedo para responder essa pergunta. ${ }^{2}$

O governo que assumiu em 2011, liderado pelo Partido dos Trabalhadores, propôs um conjunto de modalidades de participação no "Sistema Estadual de Participação Popular e Cidadã". ${ }^{3} \mathrm{O}$ mesmo era presidido por um comitê gestor paritário com membros do governo e da sociedade civil. Dentre os organismos que compunham o sistema destacam-se o Conselho de Desenvolvimento do Estado (CDES),

\footnotetext{
2 Sobre procedimentos para a consulta popular no atual governo, ver Rio Grande do Sul (2017a).

3 Ver Rio Grande de Sul (2017b).
}

com representação de diversos setores da sociedade, os Conselhos Regionais de Desenvolvimento (COREDES) e o Gabinete Digital.

$\mathrm{O}$ orçamento participativo estava integrado nesse sistema como elemento prioritário. Uma inovação importante foi a realização de plenárias regionais para discussão de prioridades para a elaboração do Plano Plurianual que serve de "moldura" para os orçamentos anuais. Os orçamentos anuais seguiam as seguintes etapas: audiências públicas regionais, nas quais se selecionavam 10 entre as 15 áreas temáticas que serviram de base para a apresentação de "demandas" nas assembleias públicas realizadas em cada município. Essas 15 áreas eram definidas no Plano Plurianual e orientavam a elaboração orçamentária no próximo quadriênio. Concretamente isso significava que se uma região elegesse a saúde como área prioritária, os projetos nessa área teriam um peso maior quando os delegados dos municípios (um delegado por cada 30 votantes) voltavam a se encontrar para definir os itens que deveriam constar da cédula na qual os eleitores assinalavam suas prioridades. Após a votação, que podia ser tanto em urnas distribuídas no município como via internet, os delegados consolidavam a proposta a ser encaminhada ao setor responsável pela elaboração do orçamento. Como o valor destinado a projetos do orçamento participativo já estavam predefinidos por região e como deveriam enquadrar-se nas diretrizes antes fixadas, tinham a sua inclusão assegurada na proposta do orçamento estadual que era por fim votada pela Assembleia Legislativa.

Convém lembrar que o orçamento participativo tem sua história nas lutas populares e inicialmente tinha como uma de suas bandeiras a "inversão de prioridades" (HORN, 1994, p. 113), ou seja, o beneficiamento da maioria da população, geralmente excluída da democracia representativa burguesa. Esse caráter revolucionário no contexto da história brasileira foi motivo de muitas disputas cujo saldo representa um acúmulo para a possibilidade de "democratizar a democracia". Em livro homônimo, Boaventura de Sousa Santos (2003) reúne experiências de várias regiões do mundo que buscam o aprofundamento da democracia através da participação popular. Trata-se de experimentos de democracia participativa que indicam 
possibilidades de construção de outras formas de organização da sociedade, talvez a emergência de um novo contrato social (STRECK, 2003, 2010).

\section{Pesquisa e relações de poder: sobre a metodologia}

A maioria dos estudos com metodologias qualitativas situa-se em âmbitos menores, muitas vezes prevenindo os leitores de que não se pretende fazer generalizações. Mesmo assim, parece inevitável que a pesquisa, com qualquer metodologia, faça parte de uma comunidade de diálogo sobre determinado tema e para isso elementos de comparação e descoberta de confluências e divergências entre estudos são inerentes à prática da pesquisa. A pesquisa-ação e a pesquisa participante, por sua vez, têm também uma tradição com estudos em larga escala (FALS BORDA, 1979; FRICKE, 2011; GAVENTA; CORNWALL, 2006).

O estudo sobre o orçamento participativo num estado do tamanho geográfico e com uma população maior do que a de muitos países pode ser vista como um experimento de pesquisa participante numa escala ampliada. Pretendeu-se analisar o orçamento participativo como um processo político-pedagógico no qual, assim se presumia, podem ser identificados sinais que apontem para alternativas ao modelo de desenvolvimento globalizado, que mostra sintomas de esgotamento em todas as regiões do mundo. Talvez estejamos de fato não apenas diante de uma crise financeira e de representação política, mas confrontados com uma crise civilizacional que requer, em termos de pesquisa, compreender o micro e o macro nas relações sociais como uma unidade.

Em termos de América Latina isso significa voltar a atenção para as potencialidades de resistência, de organização e de transformação que se encontram no povo. Sem romantizar o povo como uma entidade abstrata, vale lembrar a observação de Orlando Fals Borda (2010b, p. 216, tradução nossa) sobre a direção para onde se volta o olhar quando se pensa em alternativas para o desenvolvimento: "Os europeus, evidentemente, progrediram e se enriqueceram com o desenvolvimento técnico-científico, em grande parte às custas de nós do Terceiro Mundo. Mas isso foi também às custas de sua alma e dos valores sociais, como no contrato mefistofélico". ${ }^{4}$ A correção à forma desequilibrada e desumanizadora que o progresso tomou eventualmente poderia ser corrigida por vivências que ainda palpitam nas sociedades chamadas atrasadas, como é o caso do vivir bien ou buen vivir (Suma qamaña) dos povos originários nos Andes (HUANACUNI MAMANI, 2010).

Fals Borda referia-se a um "socialismo raizal" fundado em valores de solidariedade, de liberdade e de luta pela dignidade humana que ele via nos movimentos populares da América Latina. A trajetória desse pesquisador colombiano não permite ler nessa sua posição política qualquer sentimento xenofóbico, mas a antevisão de um período de transição paradigmática (SOUSA SANTOS, 2000) no qual pudessem coexistir diferentes formas de vida e de organização social. Por sinal, foram estes movimentos populares a que se refere Fals Borda que impulsionaram a experiência pioneira de orçamento participativo em Porto Alegre há mais de duas décadas e que, entre avanços e retrocessos democráticos, vêm mantendo viva a experiência.

Faço essa referência para caracterizar o interesse nesse campo empírico por ser um lugar importante de compreender a sociedade em movimento, e as direções desse movimento. Não sendo a pesquisa politicamente neutra, o pesquisador precisa perguntar-se sobre as ações que deseja potenciar com o seu trabalho. Segundo Zemelman (2006, p. 112, tradução nossa), "Temos que identificar as realidades potenciáveis, mas essas realidades potenciáveis não estão necessariamente inscritas em um corpus teórico, dependendo do para que eu quero conhecer, que é um para axiológico e ideológico". ${ }^{5}$ Além disso, o orçamento participativo é também o lugar onde o poder, através do manejo dos recursos públicos, e a participação popular são elementos intrínsecos ao processo.

Ao longo da pesquisa, o grupo formado por pesquisadores e estudantes de graduação e pós-

4 "Los euroamericanos, evidentemente, progresaron y se enriquecieron con el desarrollo científico-técnico, mucho a expensas de nosotros los del Tercer Mundo. Pero ello fue también a expensas de su alma y de los valores sociales, como en el contrato mefistotélico."

5 "Hay que detectar las realidades potenciables, pero estas realidades potenciables no están prescritas necesariamente en un corpus teórico, van a depender del para qué quiero yo conocer, que es un para qué axiológico o ideológico." 
-graduação participou de uma série de atividades, principalmente no papel de observadores. Colocamo-nos intencionalmente numa posição inicial de escuta, cientes de que muitas pessoas envolvidas no processo têm uma longa experiência como gestores públicos ou como cidadãos engajados em suas comunidades. Participamos, assim, de seminários de formação, da escola do governo, de audiências públicas regionais, e de assembleias municipais. Coletamos informações através de um questionário no qual buscamos a quantificação sobre o perfil dos participantes, as entidades por eles representadas, suas expectativas e frustrações com o processo. Momentos fortes da pesquisa foram as reuniões com coordenadores estaduais e regionais, e os seminários de reflexão em algumas regiões selecionadas onde discutimos os resultados emergentes e os rumos do processo. As gravações, tabelas e registros compõem o corpus que serve de base para este registro. Os excertos utilizados são extraídos das transcrições de assembleias e reuniões. ${ }^{6}$

O estudo não tinha como objetivo avaliar como as discussões e votações impactaram, no final, a alocação dos recursos e a execução das obras. A prioridade era observar e compreender a dimensão pedagógica implícita ou explícita nas atividades realizadas. Cabe, por isso, ampliar as informações sobre o processo de pesquisa que tinha a participação como um princípio metodológico. Entre as questões que emergiram estão as expectativas que tiveram que ser negociadas e os diferentes discursos através dos quais se constroem consensos ou alternativas, confluindo para a questão do poder, que faz parte tanto da pesquisa quanto da formação da cidadania no orçamento participativo.

Entende-se por poder, na linha do sociólogo Boaventura de Sousa Santos (2000, p. 266), "qualquer relação social regulada por uma troca desigual". Isso significa, por um lado, reconhecer com Foucault a capilaridade do poder em todas as relações sociais, considerando que a igualdade não pode ser considerada um estado, mas uma permanente conquista. O poder, segundo Foucault (1979), não tem apenas uma função de reprimir, mas permeia todas as relações como uma força

6 O material está disponível nos arquivos do grupo de pesquisa Mediações Pedagógicas e Cidadania, na Universidade do Vale do Rio dos Sinos (Unisinos). que produz coisas, saberes e discursos. Por outro lado, se afirmamos que o poder está em toda parte, como uma força dispersa, corre-se o risco de não o situar em lugar algum. Parece razoável, por isso, a posição de Sousa Santos (2000, p. 265) ao afirmar que "se não houver um princípio de estruturação e de hierarquização, não há um enquadramento estratégico para a emancipação". Sem essa estruturação corre-se o risco de um ativismo inconsequente ou de passividade diante do que parecerá um emaranhado de poder.

A pesquisa gerou diferentes expectativas, uma das quais foi assim manifestada:

Os dois, o moço e a moça aí, são da Unisinos, que está fazendo um trabalho de pesquisa, que vai escrever a história da participação popular no nosso Estado, desde o orçamento participativo até os demais processos. Eles estão fazendo um levantamento, eles vão deixar aí, com cada um aqui um questionário [...] para poder contar a história desse processo que é muito rico aqui no nosso estado. Nós estamos num estado pioneiro, um estado que tem história ai no processo de participação [...] (COORDENADOR REGIONAL DO VALE DOS SINOS).

Nessa apresentação de dois estudantes, membros do grupo de pesquisa presentes na reunião, $o$ coordenador regional revela a expectativa criada na região em relação à pesquisa. Embora se enfatize que a pesquisa é um processo partilhado de busca e produção de conhecimentos, seria enganoso afirmar que se está diante de um projeto codeterminado (KRISTIANSEN; BLOCH-POULSEN, 2011). Talvez fosse mais adequado usar o conceito de "pesquisa consorciada" (BRANDÃO, 2014, p. 70), na qual a partir de pressupostos comuns se desenham objetivos específicos, de forma dialogada.

$\mathrm{O}$ que basicamente promove a convergência de interesses é a intencionalidade política de aprofundamento ou radicalização da democracia. Há um reconhecimento tácito de todos os grupos envolvidos de que uma democracia não pode prescindir da participação dos cidadãos. A participação é tida como um valor, mesmo que na sua prática se reconheçam muitas falhas.

No entanto, há também uma diferenciação de objetivos. O coordenador expressa o que pode ser uma expectativa dos gestores: contar a história da participação popular, no estado e para além 
das fronteiras regionais e nacionais. Os agentes responsáveis pelo processo sabem muito bem do apagamento da história das gestões públicas por questões partidárias. Basta mencionar que um enorme volume de material do processo entre 1999 e 2002 foi confiado aos arquivos do grupo de pesquisa da universidade para prevenir a sua destruição pela administração entrante, de outro partido político. Enquanto pesquisa universitária, o grupo de pesquisa tem um interesse em resultados acadêmicos, expressos em jargão que pouco interessa aos participantes das assembleias populares. Em ambos os casos, no entanto, se amplia a reflexividade coletiva que, concordando com Eikeland (2007, p. 53, tradução nossa), é o critério básico da pesquisa-ação e pesquisa participante: "O núcleo duro da pesquisa ação não é intervenção, mas autorreflexão coletiva" ${ }^{\prime}$

A distinção que Oyvind Palshaugen (2006) estabelece entre discurso teórico e discurso prático é relevante para operacionalizar essa reflexividade coletiva, uma vez que os sujeitos envolvidos na pesquisa não apenas têm campos de atuação diferentes, mas se movimentam em campos linguísticos próprios. Segundo ele, a possibilidade de entendimento se dá a partir da capacidade do pesquisador de participar do discurso prático. Em suas palavras, "[...] o poder do conhecimento depende da habilidade do pesquisador de participar de discursos práticos com base no poder do melhor argumento, e esta habilidade por sua vez depende de um sensível poder de julgamento" (PALSHAUGEN, 2006, p. 291, tradução nossa). Ou seja, não é apenas uma questão de estratégia discursiva, mas de sensibilidade ética para avaliar os discursos.

Como compreender a pesquisa nesses jogos de poder? Por um lado, o poder da pesquisa se mistura nas disputas de poder entre os protagonistas do processo: autoridades constituídas estaduais e municipais, lideranças locais, organizações comunitárias, movimentos sociais e ONGs. Não existe uma pesquisa que possa dizer-se neutra, embora os dados e resultados por ela produzidos possam

7 "Hard core action research is not intervention but collective self-reflection."

8 " [...] the power of knowledge is dependent on the researchers' ability to participate in practical discourses based on the power of the better arguments, and this ability is in turn dependent on a sensible power of judgement." ser apropriados de formas diversas por diferentes grupos. Por exemplo, os partidários de uma participação popular ampliada podem entender os dados sobre a dificuldade de participação como uma deficiência a ser corrigida, enquanto os adversários podem interpretar os mesmos dados como um sinal do fracasso dessa proposta de participação ou ainda como sinal da inviabilidade de participação popular em contextos geográficos maiores. Esse poder de controle o pesquisador não possui sobre o seu produto.

No caso do orçamento participativo, pode-se permanecer no âmbito oficial e confirmar a intencionalidade político-pedagógica dos dirigentes. Pode-se também buscar ouvir as vozes silenciadas num processo supostamente democrático. Exemplo disso é quando se constata que o tempo destinado à fala da coordenação e das autoridades e aquele destinado aos participantes é bastante desproporcional. É muito difícil para um cidadão comum levantar numa assembleia, às vezes subir ao palco e diante de uma mesa formada por autoridades expor a sua demanda em reduzidos três minutos. O papel da pesquisa, no caso, é contribuir para inserir a voz desses cidadãos de uma forma digna num processo do qual a pesquisa se tornou parte. Há uma "diretividade" (FREIRE, 1996) que tem sua base numa postura ética que não necessariamente coincide - ou coincide parcialmente - com as posições dos participantes no processo.

Nesse sentido, a pesquisa não pode ser entendida de forma simplista como um instrumento de uma das partes envolvidas na disputa, como estando despida de uma potência própria. O envolvimento do pesquisador na reflexividade coletiva também implica interferência no processo através de suas escolhas, assim como as escolhas dos demais sujeitos e grupos interferem no projeto de pesquisa que ele coordena. Na linguagem de Bourdieu (1997, p. 52), ele dispõe de determinado tipo de "capital" que lhe permite estar presente como um agente "de fora”. Um exemplo disso é quando, numa reunião de pesquisa, um secretário de educação de um município disse que a presença do pesquisador lhes ajudava a ver melhor os problemas, a fazer perguntas melhores. Com essa resposta ele indicava a importância da pesquisa no processo, mas marcava uma posição de protagonismo da própria 
comunidade. Eles não esperavam recomendações e respostas, mas meios de fazer as perguntas que melhor conduzissem à solução.

A pesquisa sobre o orçamento participativo revela, além disso, a necessidade de transcender os parâmetros disciplinares clássicos. Essa é uma tradição da pesquisa-ação e da participante. Basta recordarmos o muito citado artigo de Kurt Lewin (1946) no qual ele argumenta que uma visão estreitamente disciplinar é incapaz de dar conta da complexidade dos fenômenos sociais. O resultado, nas próximas décadas, poderia ser um amálgama das diversas disciplinas numa só ou então a formas de cooperação. No Tavistock Institute, uma referência da pesquisa-ação na Europa, a interdisciplinaridade (TRIST, 1989) era uma marca de seu trabalho de pesquisa e formação. Orlando Fals Borda (2010a) preferia falar em convergências disciplinares, incluindo na sua pesquisa áreas pouco ortodoxas como a música e o folclore popular.

\section{Formação da cidadania e poder}

O orçamento é um lugar privilegiado para perceber a circulação do poder, uma vez que é o núcleo duro do planejamento público. Sem a alocação de recursos, os melhores projetos não passam de intenções. Ou seja, é o ponto de partida para a execução de obras e implementação de políticas públicas, cujo resultado final depende ainda de outros fatores, como a disponibilidade efetiva dos recursos, a eficiência e vontade política dos administradores e a possibilidade de controle social. Todas as etapas, desde a concepção de um projeto até a sua execução e ainda, posteriormente, o seu uso, são expressão do exercício de poder.

Valemo-nos para a análise do princípio de estruturação do poder identificado por Boaventura de Sousa Santos, conforme anteriormente mencionado, conformado por seis espaços estruturais, cada um deles reproduzindo formas específicas de poder: o espaço doméstico, onde o poder se manifesta através do patriarcado; o espaço da produção, caracterizado pelo poder de exploração do trabalho e da natureza; o espaço do mercado, onde impera o fetichismo das mercadorias; o espaço da comunidade, onde o domínio se manifesta na diferenciação desigual; o espaço da cidadania, no qual o estado exerce a dominação; e o espaço mundial, no qual o poder se expressa na troca desigual.

Em todos esses espaços também se geram contrapoderes ou poderes de resistência que, opondo-se à lógica reguladora, colocam-se como lugares de emancipação. Neste estudo do orçamento participativo, os espaços onde se observa a disputa são sobretudo a comunidade e a cidadania. ${ }^{9}$ Há a possibilidade de reconhecimento e de legitimação de novos atores políticos que expressam as necessidades de seus grupos e de suas comunidades, e se instala uma dinâmica de interação com o poder público que pode levar tanto a alianças quanto à confrontação.

Sérgio Herbert (2008) argumenta, com base em dados colhidos numa região do estado no período de 1999 a 2002, que no processo do orçamento participativo há condições que favorecem o surgimento de novas lideranças comunitárias. Ao desmistificar a autoridade, rompe-se também com a lógica tradicional de quem deve ser o líder do local ou região. Conforme Herbert (2008, p. 278), "o desvelamento da autoridade e da realidade acontecem de forma simultânea". São outras pessoas que tomam a palavra, são outras necessidades que emergem e são outros os sujeitos e as formas de interlocução. As conclusões de Cênio Weyh (2011) corroboram a tese de que o orçamento participativo pode ser uma prática renovadora de lideranças e contribui para a oxigenação da política enquanto força organizadora da sociedade.

No excerto abaixo uma professora confronta de forma incisiva as autoridades pelo fato de desconhecer ou desconsiderar a realidade local:

Gente, só para reforçar o que o Diego falou aqui, o porquê do distanciamento do que acontece na nossa cidade. Primeiro: mal divulgado que nem todo mundo tem acesso ao jornal na escola, lá na escola faz três meses que não aparece mais. Segundo: a maioria que está aqui acorda cedo, vão pegar ônibus Porto Alegre- Esteio. Vão trabalhar em outros lugares porque aqui não tem emprego para eles; então nós vamos sair da cidade dormitório e aí vem para a aula, vão para casa, deitam e dormem. (NOVA SANTA RITA).

9 A identificação de um conjunto de espaços estruturais propõe o desafio de ampliação do escopo dos estudos para a construção de uma pedagogia do poder. 
Ao mesmo tempo, essa professora busca uma forma de politizar a vida cotidiana e as relações sociais. Depois de dizer que ela trabalha três turnos do dia, levantando às 6 horas e indo dormir à meia-noite, esse esforço representa o que ela considera um ganho, não necessariamente em termos de aprovação de um projeto, mas de construção de uma consciência coletiva:

E o terceiro, acho assim: a gente nunca pode desacreditar da política, nunca pode ter vergonha de dizer: eu quero assim e eu penso assim. O título é a arma mais poderosa que a gente tem, independente de sigla partidária, de quem vai concorrer ou não vai. A gente não pode nunca se desmotivar, tem que acreditar ainda nas pessoas porque no momento em que a gente não acreditar nos outros não precisa nem viver, porque a gente vive uma vida através de sonhos, de objetivos e corre atrás. (NOVA SANTA RITA).

Esse "poder a partir de baixo" confronta os "poderes de cima". É um poder de insurgência que mobiliza os poderes constituídos, se não à ação, pelo menos à escuta. Podemos ver isso numa passagem do discurso de um presidente do COREDES. Depois de agradecer a presença de todos, ele destaca a presença de coordenadores do orçamento participativo estadual, chamando atenção para as dificuldades de sua tarefa:

Não é um papel fácil que eles têm, de ficar dando explicação em todas as regiões. As pessoas acham que as coisas acontecem de um mês para o outro ou de um ano para outro, mas eles têm a paciência pedagógica que a gente deve ter em termos de governo, em termos de COREDES, em termos de Prefeitura Municipal. (COREDES VALE DO PARANHANHA).

As duas manifestações representam lugares diferentes de articulação de poder. No caso da professora, o tom é inicialmente de indignação em relação ao distanciamento do poder público, mas ela sabiamente transforma a reclamação numa questão política. O discurso do reitor universitário, presidente do COREDES, por sua vez, enfatiza o lado pedagógico do processo, destacando o papel da participação e conscientização do povo no processo e também vindo em defesa do poder público, que precisa dar explicações ao povo e para isso necessita de paciência pedagógica.
O próprio sistema de participação, com uma grande variedade de "caixinhas", dificulta a inserção dos cidadãos nas discussões das questões maiores da sociedade. Existe o Gabinete Digital, onde são postadas geralmente manifestações pessoais. Existe também o Conselho de Desenvolvimento Econômico, que pela sua natureza congrega um número reduzido de representantes da sociedade. Existem os COREDES e os Conselhos Municipais de Desenvolvimento Econômico e Social (COMUDES), que atuam não necessariamente através do orçamento participativo. É uma realidade, por um lado, centralizadora e organizadora da participação e, por outro lado, fragmentadora. Vale dar atenção ao alerta de Boaventura de Sousa Santos (2000, p. 228), de que a combinação de fatores cósmicos (de centralização) e caósmicos (de instâncias intermediárias) pode ser responsável pela "opacidade fenomenológica das relações de poder na sociedade", dificultando a eficácia das lutas de resistência.

O orçamento participativo é, mesmo assim, o lugar de reconhecer o poder de diferentes grupos e entidades que coexistem na comunidade. Um rápido olhar sobre a lista de participantes permite ver que grande parte deles está nas reuniões para exercer algum tipo de representação. O lado positivo é a articulação prévia em torno de necessidades sentidas por setores organizados da sociedade (clubes, ONGs, escolas, hospitais, entre outras). Deve-se questionar, no entanto, quando setores públicos (secretarias de governos municipais, a polícia, corpo de bombeiros, entre outros) disputam os mesmos parcos recursos, tornando o processo um tanto endógeno e, com isso, sendo eventualmente um fator de desmobilização da comunidade.

Os outros espaços estruturais parecem menos afetados no sentido de provocar questionamentos e eventuais mudanças. No orçamento participativo entre 1999 e 2002 temos registro de maior participação de mulheres, com reivindicações que abrangiam o espaço doméstico. Com uma participação popular mais reduzida nas assembleias, encolhe o espaço das mulheres, que passam a ser representadas pelos homens. Este fenômeno também se verifica quando observarmos a participação em diferentes níveis: tanto mais elevado o nível, tanto menos se tem a presença feminina. 
Os espaços da produção, do mercado e das trocas mundiais parecem imunes ao tipo de discussão que ocorre no orçamento participativo. O governo informa no Caderno de Diretrizes do ciclo do orçamento estadual de 2013/2014 que o estado possui uma dívida de R $\$ 49$ bilhões (aproximadamente U\$ 25 bilhões) e que só do serviço da dívida foram pagos $\mathrm{R} \$ 16,8$ bilhões (em torno de U\$ 8,5 bilhões) entre 2005 e 2012, enquanto apenas $\mathrm{R} \$ 7,3$ bilhões (em torno de U\$ 3,6 bilhões) foram investidos. Ainda outros dados compõem um quadro dramático de "rigidez orçamentária", possivelmente para justificar que o total de projetos da participação cidadã recebeu um valor de $\mathrm{R} \$ 165$ milhões, que correspondem a aproximadamente $8 \%$ do total previsto para investimentos no orçamento do estado. Essas são realidades que estão fora do âmbito da discussão dos cidadãos que pagam uma dívida com gastos que às vezes pouco reverteram para o povo que participa no orçamento participativo. Não obstante, sinalizam uma intenção de transparência, um passo necessário, embora ainda insuficiente, para uma mudança na cultura política.

\section{Considerações finais}

O orçamento participativo pode ser visto como um processo pedagógico, que extrapola a coleta de demandas para eventualmente integrar o orçamento público. Ele é também, em si, um processo de pesquisa na medida em que os participantes conseguem promover a reflexividade não apenas sobre a sua realidade, mas sobre o processo de construção dos conhecimentos sobre a mesma. Olhemos, para finalizar, mais atentamente para o que podem ser alguns elementos para uma pedagogia do poder que, conforme mencionado na introdução, pode aqui ser apenas anunciada como tema.

No diálogo entre um aluno com o coordenador regional de participação vemos explicitada a intencionalidade pedagógica do orçamento participativo:

Aluna: Nós estamos em época de provas e trabalho, a gente não pode ficar perdendo tempo aqui.

Representante do Governo do Estado: Você não está perdendo tempo, você está ganhando tempo, está ganhando aprendizado. Nós estamos discutindo democracia e cidadania aqui, além de tudo acho que o que vocês estão fazendo aqui não é perda de tempo. Eu sei que é tempo de prova, mas é um processo. (NOVA SANTA RITA).

Segue-se a fala de duas alunas que desconsideram a resposta do coordenador e continuam reclamando que as informações não chegam na periferia da cidade:

As informações ocorrem somente aqui no centro, tipo bairro Sanga Funda e Berto Círio não têm informação, porque carro de som... essas coisas. Eu moro em Sanga Funda e nunca ouvi falar, nunca escutei, só fiquei sabendo hoje pelo professor Sandro.

$\mathrm{O}$ representante do governo então cede e reconhece a necessidade de mudança na forma de difundir as informações: "Nós vamos trabalhar nisso para fazer a correção para o ano que vem. O governo do estado vai ter que ampliar isso [a comunicação]." Nessa troca informal de palavras entre uma autoridade governamental e alunos de uma escola, vislumbra-se a possibilidade de uma pedagogia do poder, que está intrinsecamente interligada com uma pedagogia da participação. Destaco a seguir algumas características dessa pedagogia do poder e algumas considerações sobre a contribuição da pesquisa sobre o orçamento participativo para a sua constituição.

Uma das marcas da pedagogia de poder seria a capacitação e instrumentalização dos cidadãos para a leitura do mundo. Quando Paulo Freire (1982) afirma que a leitura do mundo precede a leitura da palavra, ele sinaliza uma intencionalidade política no sentido de que o poder pode inibir ou potenciar o "ser mais" e possibilitar a emergência dos "inéditos viáveis". Conhecer as forças que compõem a trama social é uma tarefa pedagógica tanto da pesquisa quanto do ensino formal ou não formal. No orçamento participativo temos inúmeros exemplos de como se aprofunda o conhecimento da realidade local, regional e nacional; se aprende a lidar com diferentes perspectivas sobre assuntos da comunidade e construir propostas negociadas.

Essa leitura, por seu turno, vem sempre associada à pronúncia do mundo, tanto assim que a própria pesquisa pode ser vista como uma forma de dizer a sua palavra sobre o mundo (STRECK, 2006), uma palavra que, na acepção freiriana, é palavração. 
Disso se depreende que o conhecimento não pode ser dissociado da prática. O clássico conhecer para transformar recebe uma nova interpretação no sentido de conhecer transformando, ou conhecer na transformação.

Outra marca da pedagogia do poder é reconhecer no espaço local uma instância privilegiada de educação. A pesquisa do orçamento participativo revelou a dificuldade de comunicação através dos meios de comunicação, como rádio, jornal ou carro de som. Ou o jornal não chega, ou as pessoas estão nas fábricas, lojas ou escolas e a mensagem não as alcança. Ao mesmo tempo, verifica-se o papel importante do convite pessoal. A pesquisa ratifica o que José Luis Rebellato (2009, p. 98, tradução nossa) constatou no Uruguai: "O tema de como chegar ao vizinho não organizado adquire uma relevância destacada e talvez seja uma chave fundamental para o desenvolvimento de uma democracia radical"10 São discussões que apontam para a relevância da territorialidade para a construção de uma pedagogia do poder, ou seja, a consideração dos espaços onde as pessoas organizam a sua vida e criam formas

10 "El tema de cómo llegar al vecino no-organizado adquiere una relevancia destacada y quizás es una clave fundamental para el desarrollo de una democracia radical." próprias de expressar a cidadania.

Junta-se a isso o desafio de situar os temas locais numa perspectiva global. Na medida em que os espaços de participação são reduzidos à apresentação de demandas e à votação de prioridades, essa passagem não tem condições de acontecer. Nem mesmo a enorme dívida pública é problematizada. Ela é colocada como um problema aparentemente sem solução, apenas sendo transferida para governos subsequentes. Vale para a administração pública o que Oyvind Palshaugen (2002, p. 165) reclama para as organizações no sentido de não identificar de maneira simplista a participação em discussões com a participação em decisões. A tendência, segundo ele, é de colocar o foco nos organismos de tomada de decisão e quem neles participa em detrimento do papel fundamental de discussões.

Uma pedagogia do poder será tanto uma premissa para a constituição da democracia, quanto para a sua radicalização. Ela poderia ter como horizonte a participação democrática enquanto "sabedoria dos muitos" ("die Weisheit der Vielen"] (ROTH, 2011). E sabedoria, como sabemos, implica em compreender o conhecimento e o poder recriados por uma lógica profundamente arraigada na experiência individual e coletiva.

\section{REFERÊNCIAS}

BOURDIEU, P. Razões práticas: sobre a teoria da ação. Tradução de Marisa Corrêa. Campinas, SP: Papirus, 1997.

BRANDÃO, C. Educação popular e pesquisa participante: um falar algumas lembranças alguns silêncios e algumas sugestões. In: STRECK, D. R.; SOBOTTKA; E. A., EGGERT, E. (Org.). Conhecer e transformar: Pesquisa-ação e pesquisa participante em diálogo internacional. Curitiba: CRV, 2014. p. 39-74.

EIKELAND, O. Why should mainstream social researchers be interested in action research? International Journal of Action Research, Mering, Germany, v. 3, n. 1+2, p. 38-64, 2007.

Disponível em: <http://www.ssoar.info/ssoar/bitstream/handle/document/41288/ssoar-ijar-2007-1+2-eikeland-Why_Should_Mainstream_Social_Researchers.pdf?sequence=1>. Acesso em: 18 out. 2017.

FALS BORDA, O. Historia doble de la costa. Bogotá: Valencia Editores, 1979.

La investigación en convergencias disciplinarias. In: Antologia: Orlando Fals Borda. Prefácio de José Maria Rojas Guerra. Bogotá: Universidad Nacional de Colombia, 2010a. p. 359-368.

. La investigación-acción participativa: política y epistemología. In: Antologia: Orlando Fals Borda. Prefácio de José Maria Rojas Guerra. Bogotá: Universidad Nacional de Colombia, 2010b. p. 205-225.

FOUCAULT, M. Microfísica do poder. 7. ed. Tradução de Roberto Machado. Rio de Janeiro: Graal, 1979.

FREI BETTO. A mosca azul. São Paulo: Rocco, 2006.

FREIRE, P. Pedagogia da autonomia. São Paulo: Paz e Terra, 1996.

A educação na cidade. São Paulo: Cortez, 1991. 
. A importância do ato de ler: em três artigos que se completam. São Paulo: Autores Associados/Cortez, 1982.

FRICKE, W. Socio-political perspectives on action research. Traditions in Western Europe - especially in Germany and Scandinavia. International Journal of Action Research, Mering, Germany, v. 7, n. 3, p. 248-261, 2011. Disponível em: <https://ideas.repec.org/a/rai/ijares/doi 10.1688-1861-9916 ijar_2011 03 fricke.html>. Acesso em: 15 out. 2017.

. A realistic View of the Participatory Utopia. Reflections on Participation. International Journal of Action Research, Mering, Germany, v. 9, n. 2, p. 168-191, 2013.

Disponível em: <http://www.budrich-journals.de/index.php/ijar/article/view/26726>. Acesso em: 15 out. 2017.

GALEANO, E. As palavras andantes. Tradução de Eric Nepomuceno. Porto Alegre: L\&PM, 1994.

GAVENTA, J; CORNWALL, A. Power and knowledge. In: REASON, P.; BRADBURY, H. (Ed.). The handbook of action research. Los Angeles: Sage Publications, 2006. p. 71-82.

GUIMARÃES, J. As culturas brasileiras da participação democrática. In: AVRITZER, L. (Org.). A participação em São Paulo. São Paulo: UESP, 2004. p. 197-211.

HERBERT, S. P. Orçamento Participativo na perspectiva de Freire e Gramsci: condições para emergência e formação de lideranças. Porto Alegre: Redes, 2008.

HINDMAN, M. The myth of digital democracy. Princeton: Princeton University Press, 2009.

HORN, C. H. (Org.). Porto Alegre: o desafio da mudança. Porto Alegre: Ortiz, 1994.

HUANACUNI MAMANI, F. Vivir bien/buen vivir: filosofía, políticas, estrategias y experiencias regionales. La Paz: Instituto Internacional de Integración, 2010.

KRISTIANSEN, M; BLOCH-POULSEN, J. Participation as enactment of power in

dialogic organizational action research: reflections on conflicting interests and

actionability. International Journal of Action Research, Mering, Germany, v. 7, n. 3, p. 347-380, 2011. Disponível em: <http://www.ssoar.info/ssoar/handle/document/41430>. Acesso em: 17 out. 2017.

LEWIN, K. Action Research and Minority Problems. Journal of Social Issues, Washington DC, v. 2, n. 4, p. 34-46, 1946. Disponível em: <https://doi.org/10.1111/j.1540-4560.1946.tb02295>. Acesso em: 15 out. 2017.

MARQUES, J. L. (Org.). Rio Grande do Sul: estado e cidadania. Porto Alegre: Palmarinca, 1999.

MARQUES, J. O.; BRUM, A. Uma comunidade em busca de seu caminho. 2. ed. ampliada. Ijuí, RS: Unijuí, 2002.

PALSHAUGEN, O. Constructive practice and critical theory: the contribution of action research to organizational change and the discourse of organizations. International Journal of Action Research, Mering, Germany, v. 2, n. 3, p. 283-318, 2006. Disponível em: <http://www.ssoar.info/ssoar/handle/document/41420>. Acesso em: 17 out. 2017.

Discourse-democracy at work: on public spheres in private enterprises. Concepts and Transformation, Amsterdam, v. 7, n. 2, p. 141-192, 2002. Disponível em: <https://doi.org/10.1075/cat.7.2.03pal>. Acesso em: 16 out. 2017.

PIKETTI, T. Capital in the twenty-first century. Cambridge, Massachusetts: The Belknap Press of Harvard University Press, 2014.

REASON, P. Justice, sustainability and participation. Concepts and Transformations, Amsterdam, v. 7, n. 1, p. 7-29, 2002. Disponível em: <https://doi.org/10.1075/cat.7.1.03rea>. Acesso em: 16 out. 2017.

REBELLATO, J. L. Intelectual radical. Montevideo: Extensión-Eppal-Nordan, 2009.

RIO GRANDE DO SUL. Consulta popular. Porto Alegre, 2017a. Disponível em: < http://www.consultapopular. rs.gov.br/>. Acesso em: 18 out. 2017.

18 out. 2017.

Consulta popular. Porto Alegre, 2017b. Disponível em: <http://www.participa.rs.gov.br $>$. Acesso em:

ROTH, R. Bürgermacht: eine streitschrift für meher partizipation. Hamburg: Körber-Stiftung, 2011.

SIEDENBERG, D. R. Concepções de planejamento regional e a consolidações dos COREDES. In: THEIS, I. 
Desenvolvimento e território: questões teóricas, evidências empíricas. Santa Cruz do Sul, RS: EDUNISC, 2008. p. 186-207.

SOBOTTKA, E. A.; SAAVEDRA, G.; ROSA, V. da. Legalidade, legitimação e democratização no orçamento público estadual. In: STRECK, D. R.; EGGERT, E.; SOBOTTKA, E. A. (Org.). Dizer a sua palavra: educação cidadã, pesquisa participante e orçamento público. Pelotas, RS: Seiva, 2005. p. 55-84.

SOUSA SANTOS, B. de (Org.). Democratizar a democracia: os caminhos da democracia participativa. 2. ed. Rio de Janeiro: Civilização Brasileira, 2003.

. A crítica da razão indolente: contra o desperdício da experiência. São Paulo: Cortez, 2000.

SOUZA, B. Todo o poder emana do povo. Pelotas, RS: EDUCAT, 2002.

STRECK, D. R. Educação para um novo contrato social. Petrópolis, RJ: Vozes, 2003.

A new social contract in a Latin American education context. New York: Palgrave McMillan, 2010.

. Pesquisar é pronunciar o mundo: notas sobre método e metodologia. In: BRANDÃO, C. R.; STRECK, D. Pesquisa participante: o saber da partilha. São Paulo: Ideias \& Letras, 2006. p. 250-276.

. Participation in social research: "Quijotism"or construction of a world view? International Journal of Action Research, Mering, Germany, v. 9, n. 2, p. 192-208, 2013.

TRIST, E. Culture as a psyco-social process. The Social Engagement of Social Science, v. 1, p. 539-545, 1989. Disponível em: <http://www.moderntimesworkplace.com/archives/archives.html>. Acesso em: 20 jun. 2014.

WEYH, C. B. Educar pela participação: uma leitura político-pedagógica do orçamento participativo estadual no município de Salvador das Missões/RS. Santo Ângelo: FURI, 2011.

ZEMELMAN, H. El conocimiento como desafío posible. México, DF: Instituto Pensamiento y Cultura en América Latina, 2006.

Recebido em: 08/02/2017

Aprovado em: 12/10/2017 